\title{
Interface entre Educação, Ambiente e Tecnologia: Articulação na Formação de Professor
}

\author{
Interface between Education, Environment and Technology: \\ Articulation in Teacher Training
}

\author{
Maria de Nazaré dos Remédios Sodré, NECAPS/UEPA, marinazdre@gmail.com \\ Neriane Nascimento da Hora, NECAPS/UEPA, neri.dahora@gmail.com
}

\begin{abstract}
Resumo: Este trabalho consta de uma proposta voltada aos alunos de graduação, buscando interagir com os recursos do cotidiano, como os gibis associados ao uso do computador na educação e a pedagogia de projeto, com ênfase em educação ambiental. Tem como objetivo contribuir na formação de futuros educadores, a partir do desenvolvimento de habilidades relacionadas ao uso de recursos pedagógicos. Foram realizados cinco minicursos, efetivando a seleção e leitura de gibis até chegar à fase final com a utilização do software HagáQuê na construção de novas histórias em quadrinhos (HQ's). Os relatos dos alunos indicam que o projeto Gibis exigiu o manuseio de habilidades e oportunizou a aprendizagem a partir de um tema/problema, que conduziu todo o percurso teórico e prático necessário para montar uma nova história.
\end{abstract}

Palavras-chave: formação inicial, projeto de aprendizagem, software educativo, educação ambiental.

Abstract: This work consists of a proposal carried out with undergraduates, seeking to interact with resources of everyday life as comic books associated with the use of computers in education and project's pedagogy, with an emphasis on environmental education. It aims to contribute to the training of future educators, as from development of skills related to the use of teaching resources. Five mini-courses were conducted, beginning with the selection and reading comic books until we reach the final stage using the software HagáQuê to the construction of new comics (comic books). The reports from students indicate that the Gibi's project required skills development and provided an opportunity to learn from one topic / problem that led all the necessary theoretical and practical route to create a new story.

Keywords: initial training, learning project, educational software, environmental education.

\section{INTRODUÇÃO}

Com vistas à articulação teórica e prática na formação inicial de professor, a disciplina "Prática Docente I" do curso de Ciências Naturais, e, "Biologia e Metodologia do Ensino de Ciências" do curso de Pedagogia, vivenciamos momentos discursivos sobre a habilidade do ensino e aprendizagem para além da sala aula, por intermédio do projeto "Computadores, gibis e uma prática em educação ambiental: uma vivência pedagógica por meio de projeto de aprendizagem”.

Com esse projeto, ampliamos possibilidades no campo investigativo, daí a origem e a realização dele, visando contemplar "à necessária coerência entre o saberfazer e o saber-ser-pedagógico” (FREIRE, 1996, p. 7). 
Entre as possibilidades metodológicas, priorizamos a realização do projeto de aprendizagem, por considerá-lo relevante na formação de professor, uma vez que ele enfatiza a aprendizagem interdisciplinar e é centrada no aluno. Nesta atividade, a finalidade foi trabalhar com história em quadrinhos como meio de favorecer o desenvolvimento de ideias e/ou conceitos, com ênfase em educação ambiental, existentes nos gibis que circulam no nosso dia a dia.

Dessa forma, o objetivo deste projeto foi evidenciar quais conteúdos e temas em que o professor possa de fato orientar no trabalho com alunos no processo de investigação, a partir da diversidade de conhecimentos existentes nas histórias em quadrinhos. As ações desenvolvidas tiveram como questionamentos "O uso da tecnologia favorece a construção, organização difusão da informação educacional?” e “Que relevância pedagógica teve os elementos do projeto Gibis?”

Com este fazer, ponderamos que os participantes conseguiram integrar teoria e prática, pois a intenção do trabalho visava a uma extensão educativa voltada para a formação dos graduandos e contribuição à prática (ação), com a perspectiva de formar para estimular a criatividade e a produtividade, de modo a promover, nos participantes, situações de aprendizagem, e estes a utilizarem em suas futuras artes de sua docência.

Neste trabalho, como tema/conteúdo relacionados às questões socioambientais, compartilhamos com Lucie Sauvé (2005), que, no que diz respeito às práticas em Educação Ambiental (EA), resgata a corrente moral/ética, em que a relação com o meio ambiente deve estar baseada em um conjunto de valores conscientes e harmônicos entre si. A educação ambiental, portanto, deve abranger as estratégias de desenvolvimento da sociedade, bem como ressaltar a importância dos princípios éticos, de justiça social e de cidadania, buscando superar os desafios cotidianos na formação docente.

Este trabalho discute sobre a identidade do educador, apresenta os fundamentos básicos dos elementos constituintes do tripé que norteia toda a proposta, isto é; o projeto de aprendizagem, o computador (software) e os gibis. Trata, ainda, sobre o fazer integrado com base na tríade da ação; aponta os resultados da prática pedagógica, destacando o produto final da ação - novas histórias em quadrinhos (HQ's) e as concepções dos participantes sobre a vivência e, por fim, sintetiza algumas ideias conclusivas.

\section{FUNDAMENTOS BÁSICOS DOS ELEMENTOS INTEGRADORES}

Apresentamos algumas noções básicas relevantes para esclarecimentos com relação aos elementos (tríade) que compõem a estrutura deste trabalho.

\subsection{O PROJETO DE APRENDIZAGEM (PA)}

Uma importante iniciativa metodológica na educação é aprender com projetos. Nas escolas, deparamo-nos, na maioria das vezes, com atividades que exigem certa criatividade e, para isso, é preciso enfrentar novos desafios e, principalmente, não ter medo de errar. Ser criativo depende, antes de tudo, de autoconfiança e confia nça no outro. Isto vem sendo favorecido por meio da pedagogia de projeto.

A opção metodológica por projetos educacionais vem sendo discutida e realizada por pesquisadores, como Fagundes (1999); Hernández (2000); Moran (2000); Perrenoud (2000); Valente (1993). Aprender por projeto é uma forma inovadora de romper com as tradições educacionais, proporcionando um formato mais ágil e participativo ao trabalho docente. Para Fagundes et al. (1999), é mais do que uma estratégia fundamental de aprendizagem, sendo um modo de ver o ser humano construir, 
aprendendo pela experimentação ativa do mundo, versa de uma metodologia em que o aluno passa a ser protagonista da aprendizagem. Nesta abordagem, o estudante tem a oportunidade de construir conhecimento a partir da exploração de uma questão de investigação.

O PA proporciona selecionar informações, gerando aprendizagem com construção de novos conhecimentos que tenham um significado, corroborando para o raciocínio lógico sobre esse significado, enquanto elabora síntese de respostas descritivas e explicativas para a curiosidade investigada (FAGUNDES, 2006).

Moran (2000) considera que se faz necessária a articulação com a experiência individual, abrindo, assim, espaço para a definição do PA, sem um distanciamento entre o ensino, a aprendizagem e a vida. Neste caso, há exigência do comprometimento dos alunos com o projeto, pois envolve uma mobilização dos sujeitos, com a finalidade de êxito. Neste enfoque, o PA deve ser considerado um instrumento fundamental no processo de formação do professor e ainda impedir o tratar do conhecimento por meio de pacotes prontos.

\subsection{O COMPUTADOR E O SOFTWARE EDUCACIONAL}

Outro meio de contribuir e incentivar a aprendizagem, nas últimas quatro décadas, nas instituições de ensino, em nosso meio, é o computador. O seu uso, na educação, deve ser considerado como artefato de ampliação das funções do professor, favorecendo mudanças nas condições e no processo de ensino aprendizagem. A sua utilização, na escola, não pode limitar apenas ao treinamento de professores no uso de mais uma tecnologia e ao uso de softwares educativos. O importante é que o professor aproprie-se dessa tecnologia, descobrindo as possibilidades de uso que ela permite na aprendizagem do aluno, favorecendo, assim, o repensar do próprio ato de ensinar.

Trata-se, portanto, de compreender o computador como um forte aliado para desenvolver projetos e trabalhar temas geradores ou qualquer outro tipo de abordagem educativa que o educador queira escolher, promovendo o respeito às particularidades d $\mathrm{e}$ todos os envolvidos no "ato de educar", criando uma cumplicidade e um comprometimento de todos.

Segundo Valente (2003), a implantação dos recursos tecnológicos de forma eficaz na educação exige quatro ingredientes básicos; o computador, o software educativo, o professor capacitado e o aluno, sendo que nenhum se sobressai ao outro. O computador não é mais o "instrumento que ensina o aprendiz, mas a ferramenta com a qual o aluno desenvolve algo e, portanto, o aprendizado ocorre pelo fato de estar executando uma tarefa por intermédio do computador” (VALENTE, 1993, p. 13).

Visão semelhante resgatada por Moran (2000), quando discute sobre a mediação pedagógica e o uso da tecnologia no processo de aprendizagem, em que destaca elementos como o aprender, voltado para um "sujeito" que adquire uma aprendizagem significativa e apresenta mudança comportamental; o aluno, que realiza a autoaprendizagem, um aprendiz ativo e participante, com uma ação colaborativa; o professor, como mediador do conhecimento e favorecendo meios para o ato colaborativo; a tecnologia, que permite uma variabilidade de sua aplicação junto ao processo de aprendizagem. Assim, as novas tecnologias podem ser aliadas na mediação pedagógica e na construção do conhecimento significativo.

O software que serviu como suporte para a realização do projeto foi o HagáQuê desenvolvido de modo a facilitar o processo de criação de uma história em quadrinhos por uma criança ainda inexperiente no uso do computador. O HagáQuê é um software educativo de apoio à alfabetização e ao domínio da linguagem escrita, e é resultante da 
dissertação de mestrado intitulada "HagáQuê - Editor de Histórias em Quadrinhos" produzida por Sílvia Amélia Bim, no Instituto de Computação/UNICAMP.

\subsection{OS GIBIS COMO RECURSO PEDAGÓGICO}

A publicação de revistas próprias de histórias em quadrinhos, no Brasil, começou no início do século XX, sobre forte influência estrangeira e com o mercado editorial dominado pelas publicações de quadrinhos americanos, europeus e japoneses.

Carvalho (2006) acrescenta que é cada vez maior o número de professores que descobrem nas HQ's um recurso relativamente barato e interessante para se aproximarem de seus alunos. Historicamente, sempre surgiu preconceito em relação aos quadrinhos e tendo como argumento; são violentos, têm pouca profundidade, ensinam crianças a ter comportamentos bizarros. No entanto, enquanto os países do primeiro mundo rapidamente provaram que tais argumentos não eram válidos, e enxergaram o potencial dos gibis. Nos países em desenvolvimento, isso demorou mais a acontecer, mas felizmente, está acontecendo.

Feijó (1997) indica que, em relação aos quadrinhos, foram necessários mais de cem anos para que alguém conseguisse ver o óbvio; as histórias em quadrinhos não são uma leitura exclusiva de crianças ou algo "bobinho", uma sub-arte. São muito mais.

Mendes (1990) lista três possibilidades interessantes de utilização didática das histórias em quadrinhos: a análise crítica das histórias feita em conjunto com a criança; o incentivo à criação de histórias em quadrinhos pela própria criança, expressando a sua visão de mundo particular e a utilização das mesmas, como um meio de expressão e conscientização política.

Hoje, várias publicações nacionais como livros didáticos, revistas, jornais e provas de processos seletivos para as universidades, apontam sugestões para o trabalho com as histórias em quadrinhos no contexto da sala de aula, inclusive documentos oficiais como os Referenciais Curriculares para a Educação Infantil e os Parâmetros Curriculares Nacionais para o Ensino Fundamental.

\section{A ATIVIDADE INTEGRADORA COM BASE NA TRÍADE ESTABELECIDA NA AÇÃO - O FAZER}

A conexão gibis, computador (software) e o projeto de aprendizagem teve a perspectiva de constituir-se em uma proposta de formação inicial de professor, utilizando-se como suporte a pesquisa, com a qual todos estariam em condições de atualizar e ampliar seus conhecimentos voltados para questões da educação ambiental. Para a elaboração desse conhecimento, fez-se necessário um trabalho articulado às habilidades e competências, no sentido de construir um caminho possível à criatividade e inovação que desse um significado ao processo de formação, de modo a colocar cada participante como protagonista da situação de aprendizagem.

O estudo, por parte do pesquisador, constou de uma integração entre ensino/pesquisa, e teve como sujeitos vinte professores em formação inicial. Optamos pela pesquisa-ação, por ela proporcionar um intercâmbio entre os atores sociais e os aspectos social, educacional, técnico ou outro, de forma a compreender que a pesquisaação contribui para mudança no contexto escolar (THIOLLENTT, 2008).

A pesquisa-ação educacional é, principalmente, uma estratégia para o desenvolvimento de professores e pesquisadores de modo que possam utilizar suas pesquisas para aprimorar seu ensino e em decorrência, o aprendizado de seus alunos (TRIPP; WILSON, 2001). 
Quanto aos projetos de cada grupo de trabalho-GT, foram realizados por meio da pesquisa teórica, que, segundo Tchizawa e Mendes (2006), visa à compreensão e discussão da revisão da literatura. Nesse sentido, cada GT fundamentou sua questão de investigação (dúvidas temporárias) definida nos projetos de aprendizagem pelos alunos.

Foi utilizado um modelo de projeto de aprendizagem, já definido em outros trabalhos por pesquisadores, registros das falas obtidos em várias rodas de conversas com emissão de opiniões sobre a relevância do projeto na formação inicial de professor, o software educacional Hagáquê e os gibis como fonte de leitura e definição dos problemas de investigação sobre questões socioambientais neles existentes, gerado por cada grupo de trabalho. A interpretação dos dados foi de forma qualitativa e descritiva.

Foram realizados 05 (cinco) minicursos com carga horária de 40 horas, com um encontro semanal durante cinco meses. Neste período, ocorreram discussões temáticas sobre as questões de investigação do projeto, que teve como resultado a elaboração de um gibi intitulado "A turma da Lilica em Práticas de Educação Ambiental”, publicado em 2013. A seguir, uma sinopse dos minicursos:

a) Organizando e refletindo ideias construtoras da identidade do educador: constou de uma dinâmica que deu visibilidade sobre o "eu" e o "nós" dos vindouros professores, no sentido de estabelecer uma identidade dos alunos quanto à sua futura ação docente, na perspectiva de Paulo Freire. Assim, foi obtido o perfil dos alunos, e isto sinalizou que a sua formação inicial está apta a acontecer, contribu indo para o ato da reflexão, um requisito fundamental para a prática docente que possa gerar profissionais críticos. Quanto a esta questão, relacionamos com a ideia de Freire (1996, p. 39), quando relata que "é pensando criticamente a prática de hoje ou de ontem que se pode melhorar a próxima prática”.

b) Como construir histórias em quadrinhos - um recurso pedagógico: esta fase teve por objetivo estabelecer fundamentos necessários para o planejamento de cada história em quadrinhos a ser elaborada pelos participantes da oficina em seus respectivos grupos de trabalhos-GT. O conteúdo explorado foi sobre os tipos de balões e onomatopeias, definição de cenários, de personagens, roteiros, cores, etc., que, juntos, iriam agrupar conhecimentos para estruturar o plano de construção das HQ's. Surgiram, então, onze personagens, e o grupo, no coletivo, decidiu pelo nome de cada um. Dessa forma, temos; Professora Ana, Jamile, Leco, Beto, Lilica, Luquinha, Jorge, Guto, Bela, Indiazinha e cadeirante, que se articulam em um diálogo na elaboração de cada HQ.

c) Definição dos saberes encontrados e selecionados nos gibis: esse minicurso foi necessário para permitir que os alunos dessem a formatação inicial do seu produto final (nova história em quadrinhos) como culminância desta atividade. O passo inicial se deu com leituras de alguns gibis escolhidos por cada GT. É indiscutível que essa vivência com gibis tornou-se um momento prazeroso, estimulou ideias e a imaginação. $\mathrm{O}$ comando que orientou a dinâmica da leitura foi que cada GT identificasse saberes socioambientais existentes nos gibis. A partir disso, cada grupo escolheu um desses saberes, como sendo aquele que mais lhe causou curiosidade, provocou a formalização de questões problemas e ficou como o saber selecionado para então originar o projeto de aprendizagem de cada GT, e destes, como resultado da pesquisa dos alunos, uma nova história em quadrinhos, conforme apresentado na tabela 1. 
Tabela 1- Definição dos saberes socioambientais encontrados nos gibis e nas novas HQ's

\begin{tabular}{|c|c|c|c|}
\hline Grupo & Revista lida & Saber encontrado & Nova HQ \\
\hline GT1 & Vamos salvar a natureza & Desmatamento & A terra pede S.O.S. \\
\hline GT2 & $\begin{array}{c}\text { Turma da Mônica: por } \\
\text { um mundo melhor }\end{array}$ & Reciclagem de lixo & $\begin{array}{c}\text { Turminha da Lilica em: } \\
\text { aprendendo na TV }\end{array}$ \\
\hline GT3 & $\begin{array}{c}\text { Turma da Mônica: água } \\
\text { boa para beber }\end{array}$ & Descarte de lixo & $\begin{array}{c}\text { Turma da Lilica: pilhas e } \\
\text { baterias, qual é o seu destino } \\
\text { correto? }\end{array}$ \\
\hline GT4 & $\begin{array}{c}\text { Turma da Mônica: água } \\
\text { boa para beber }\end{array}$ & $\begin{array}{c}\text { Água, saneamento e } \\
\text { saúde }\end{array}$ & E no sítio da vovó \\
\hline GT5 & $\begin{array}{c}\text { Pato Donald: abaixo 0 } \\
\text { velho }\end{array}$ & $\begin{array}{c}\text { Embelezamento da } \\
\text { cidade }\end{array}$ & A praça é nossa \\
\hline
\end{tabular}

A partir desse quadro, cada GT passou a definir as dúvidas temporárias relacionadas com o saber selecionado nesta atividade, o que originou as questões de investigação para cada um dos projetos que estão apresentados na tabela 2.

Tabela 2 - Definição da questão de investigação de cada GT (dúvidas temporárias)

\begin{tabular}{|c|c|}
\hline Saber selecionado & Dúvidas temporárias \\
\hline Desmatamento & $\begin{array}{c}\text { Quais as consequências para o planeta terra } \\
\text { com a continuação do desmatamento? }\end{array}$ \\
\hline Reciclagem de lixo & De que maneira podemos reciclar o lixo? \\
\hline Descarte de lixo (pilhas e baterias) & Qual o lugar apropriado para pilhas e baterias \\
\hline Água, saneamento e saúde & $\begin{array}{c}\text { Quais são as doenças de veiculação hídrica } \\
\text { mais frequentes? }\end{array}$ \\
\hline Embelezamento da cidade & Cadê a árvore que estava aqui? \\
\hline
\end{tabular}

d) Elaboração do projeto de aprendizagem (PA): com o subtema já escolhido por cada grupo, foi delineada cada questão de investigação, o que deu visibilidade àquilo que realmente os alunos queriam pesquisar, fundamentando-se por meio da pesquisa teórica. Nessa etapa, os alunos expressaram suas ideias e conhecimentos sobre o problema em questão, definiram os passos a serem percorridos durante o trabalho, como meio condutor de cada projeto, que, de acordo com Moran (2000, p. 109), estes passos constituem-se em uma "minuta de um contrato didático", com uma postura crítica e reflexiva, na busca de um consenso das ideias apresentadas nos grupos.

Para a construção de cada PA foi utilizado um modelo que compreende um roteiro numa versão bastante simplificada, a qual promove um direcionamento no 
percurso dessa elaboração. É um instrumento implantado pelo Laboratório de Estudos Cognitivos do Rio Grande do Sul, que serviu como recurso para muitos trabalhos na área educacional, voltado para a aprendizagem de crianças e adolescentes. A opção por esse instrumento justifica-se pelo fato de que a intenção pedagógica do trabalho desenvolvido iria proporcionar uma metodologia facilitadora da aprendizagem, uma vez que a formação dos professores em questão consiste em desenvolver atividades docentes com alunos das séries iniciais do ensino fundamental e ensino infantil.

Este minicurso teve como culminância a socialização dos cinco projetos de aprendizagem, com os títulos definidos na tabela 1, citada anterio rmente, encontrados na coluna "Nova HQ".

e) Explorando o software HagáQuê: a decisão pela escolha deste software resultou em uma pesquisa na Internet, com o fim de selecionar um programa exequível à realização das produções, isto é, das novas HQ’s. Optamos pelo software HagáQuê por se tratar de um editor de histórias em banda desenhada (BD) com um banco de imagens, tendo diversos componentes para a construção de uma BD (cenário, personagens, etc) e vários recursos de edição destas imagens. Após a exploração do software, constatamos que suas ferramentas aguçam, também, a criatividade adulta, além de abrir um leque de buscas de figuras em outros arquivos da Internet, e a própria criação de desenhos e paisagens que podem ser importados para a construção de uma HQ, no HagáQuê.

4. O produto da ação (as HQ's): a produção dos graduandos ocorreu a partir das leituras dos gibis do nosso cotidiano, visando ampliar a inspiração nos GT’s. Assim, a leitura diversificada dos gibis favoreceu mais a chuva de ideias. Com a construção das novas historinhas, foi obtido um produto físico que consiste em cada nova HQ, e o produto cognitivo que manifesta uma aprendizagem a partir da construção de novos conhecimentos por meio do processo de colaboração, seus significados e reestruturação do raciocínio lógico (FAGUNDES, 2006). Para isto, foram necessários alguns procedimentos, como escolher, definir, selecionar, esquematizar, sintetizar, ampliar, filtrar informações, transferir, entre outras mais que justificam uma elaboração mais requintada e com sentido.

Esta ação foi realizada a partir do conhecimento de que a utilização de gibis como recurso pedagógico não é algo novo, bem como das inúmeras críticas quanto a esta alternativa metodológica ao longo da sua aplicabilidade na educação. Ainda assim, a opção em reunir a tríade computador, gibi e projeto de aprendizagem em uma ação formativa de professor é relevante, uma vez que esta iniciativa teve por finalidade indicar caminhos de como é possível juntar a pedagogia, a tecnologia e recursos do cotidiano, como os gibis para ganhos na aprendizagem.

Este fazer resultou em um gibi com cinco histórias em quadrinhos (HQ), sendo que uma delas "Turminha da Lilica em: aprendendo na TV" está apresentada abaixo com uma das suas tirinhas.
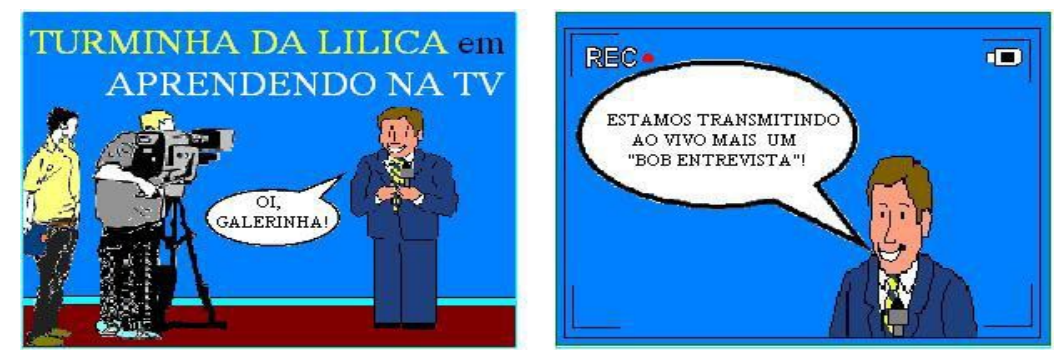

Figura 1- Tirinha de uma HQ produzida pelos alunos 


\section{RESULTADOS DA PRÁTICA PEDAGÓGICA}

Apresentamos alguns resultados mais relevantes da realização deste projeto originadas das falas dos participantes, durante as dinâmicas das rodas de conversas, como processo de avaliação, direcionadas por algumas questões motivadoras das discussões.

Com relação à contribuição da articulação computador, gibis e projeto de aprendizagem, os alunos, um grupo de 20 (vinte) estudantes que participaram efetivamente das ações previstas no projeto, acreditam na possibilidade de que esta articulação contribuiu significativamente para a construção do conhecimento sobre questões socioambientais.

Ainda nesse sentido, foi assinalado que a autonomia dos alunos na busca do conhecimento forneceu para os professores em formação recursos que estimularam a criação e a produção, seja desenhando, pintando ou escrevendo os diálogos da história. Possibilitou, além disso, que eles pesquisassem sobre os assuntos que gostariam de abordar na história para poderem montar os seus próprios diálogos que foram usados na HQ, ou seja, por meio da história em quadrinhos, o aluno construiu sua própria aprendizagem, tornando o processo educacional mais significativo.

No que se refere ao uso do software HagáQuê, os alunos afirmam que ajudou na elaboração de histórias em quadrinhos bem diversificadas e atrativas. O projeto Gibis exigiu o manuseio deste software e o conhecimento necessário sobre a linguagem dos quadrinhos, para montagem das histórias. Embora o software HagáQuê oportunize a criação de HQ’s de forma simples e rápida, a partir dos seus comandos acessíveis, é possível importar sons, imagens e cenários de outros programas e/ou arquivos, o que acaba promovendo a integração entre diferentes ações, estimulando a vontade em concluir cada etapa desafiadora desta construção. Este projeto veio ratificar que a tecnologia é uma ferramenta metodológica para o professor e uma aliada poderosa no contexto educacional.

Considerando a dinâmica na confecção de gibis, foi relatado que o projeto oportunizou a aprendizagem partindo de um tema/problema de importante aquisição na formação acadêmica dos participantes, pois auxiliou na utilização da história em quadrinhos como recurso pedagógico. Os Gibis passaram a ser visto pelos participantes como um importante recurso pedagógico muito interessante e produtivo, pois estimula a criatividade, a expressão de ideias; ensina novas formas de usar o computador e a Internet de maneira divertida; facilita a discussão de temas polêmicos e ne cessários de forma lúdica e de fácil divulgação. Logo, ao ser utilizada a linguagem dos quadrinhos na escola, o professor estará partindo de algo que faz parte do cotidiano do aluno de algo que ele gosta e conhece.

Quanto à vivência no projeto, foi exposto pelo grupo de alunos o incentivo em utilizar um objeto do convívio de todos, como os gibis, e associá-lo a um programa de computador, duas coisas comuns e atrativas às crianças. Revelaram, também, que a aprendizagem e a metodologia proposta nas ações do projeto em questão possibilita a ampliação de metodologias de ensino na escola e na conscientização de que não é difícil, nem caro, inovar na educação e assim tornar possível educar as crianças de forma lúdica, criativa, interessante e participativa.

Com esta experiência, os integrantes do projeto, assinalam uma formação participativa, contextualizada, ética e política. Nesse sentido, a formação de professor pode a partir da integração da tríade em questão; produzir, assimilar e difundir conhecimentos de educação ambiental, voltada para a compreensão e articulação dos aspectos econômicos, sociais, políticos e culturais ao aspecto ambiental. 


\section{ALGUMAS IDEIAS CONCLUSIVAS}

Aqui estão algumas ideias que julgamos, a partir do caminho percorrido nesta ação, responder às questões de investigação da pesquisa, levando em consideração os resultados dos diálogos e avaliações, sempre presentes durante a construção do conhecimento em foco.

No que se refere à questão "O uso da tecnologia favorece a construção, organização e difusão da informação educacional?”, entendemos que a tecnologia é considerada como um instrumento determinante na comunicação e construção do conhecimento, melhorando o nível da informação na educação escolar de forma a beneficiar a aprendizagem e a pesquisa.

Além disso, permite a inserção de dados advindos da internet, da produção própria de figuras, desenhos, fotos, imagens, que com esta ação, promova o pensar e a lógica no ato de criar, armazenar, transferir de forma a ampliar as possibilidades oferecidas pelo software HagáQuê. Portanto, a tecnologia aumenta o acesso à informação, envolve produção e compartilha conhecimentos, comportando-se como um poderoso e eficiente meio de comunicação, que possibilita de um simples compartilhamento de recursos, ao acesso à grande rede mundial - a Internet. Com a evolução crescente das tecnologias, as redes de computadores passam a ser o principal veículo de comunicação, pois estes novos serviços, dentre outras vantagens, facilitam ainda mais a interação entre pessoas e a interação delas com um mundo de informações.

Com relação à questão "Que relevância pedagógica teve os elementos do projeto Gibis?”, este promoveu o conhecer e o aprender a utilizar um software, isto com certeza, tornou a atividade prazerosa, além de fornecer para os alunos recursos que os estimularam a criar e a produzir. Neste caso, o computador, os gibis e o projeto de aprendizagem favorecem esse diálogo na construção do conhecimento.

Dessa forma, esta experiência auxiliou aos professores em formação inicial, a utilização de quadrinhos com seus futuros alunos, destacando que os mesmos merecem maior interesse dos educadores, já que vários pontos foram apresentados sobre seus benefícios para a educação, desafiando sua possível utilização como material didático, incluindo seu vasto potencial artístico-educacional.

Esta vivência, como outras já existentes, contribuiu para a quebra de antigos paradigmas, e para que os quadrinhos façam parte do processo de aprendizagem, como relevante na formação de professores, por compreender que a sua atuação, com o envolvimento das questões discutidas na realização deste projeto possam inspirar, como cidadãos, a construção/garantia desse processo de ensino/aprendizagem.

Nesse sentido, adotar uma posição construtivista e contextualizada foi o ponto de integração entre computador, gibis e o projeto de aprendizagem, por meio de uma ação investigativa, sustentada pelos eixos norteadores do projeto.

\section{REFERÊNCIAS BIBLIOGRÁFICAS}

CARVAlHO, Djota. A Educação está no Gibi. Campinas, SP: Papirus, 2006.

FAGUNDES, L. et al. Aprendizes do Futuro: as inovações começaram! Coleção Informática para a Mudança na Educação. MEC/SEED/PROINFO, Brasília: 1999.

FAGUNDES, L. et al. Projetos de Aprendizagem - Uma experiência mediada por ambientes Telemáticos”. Revista Brasileira de Informática na Educação. 2006. 
FREIRE, P. Pedagogia da Autonomia: saberes necessários à prática educativa. 25. ed. São Paulo: Paz e Terra, 1996.

GOLEMAN, Daniel. Inteligência emocional. São Paulo: Objetiva, 1996.

HERNÁNDEZ, Fernando. Transgressão e mudança na educação: os projetos de trabalho. Porto Alegre: Artmed, 2000.

MENDES, M. R. S. El Papel Educativo de los Comics Infantiles: (Análisis de los Estereotipos Sexuales). Tese de Doutorado, Facultad de Ciencias de la Información da Universidad Autónoma de Barcelona. Barcelona., 1990.

MORAN, J. M. Ensino e aprendizagem inovadoras com tecnologias audiovisuais e telemáticas. In: J. M. Moran. M. T. Masetto e M. A. Behrens (Orgs.). Novas tecnologias e mediação pedagógica. São Paulo: Papirus, 2000.

PERRENOUD, Philippe. Pedagogia diferenciada: das intenções à ação. trad. Patrícia C. R. Porto Alegre: Ates Médicas Sul, 2000.

THIOLLENTT, M. Metodologia da pesquisa-ação. São Paulo: Cortez, 2008.

TRIPP, D.; WILSON, J. Critical incidents in action research in education. In: SANKARAN, S. et al. Ef Effective change management gemente using action research and action learning: using action research and action learning concepts, frameworks, processes and applications. Lismore: S.C.U.P., 2001.

VALENTE, J. A. Computadores e conhecimento: repensando a educação. Campinas: UNICAMP, 1993.

VALENTE, J. A. (Org.). Formação de educadores para o uso da informática na escola. Campinas, SP: Unicamp/Nied, 2003.

VERGUEIRO, Waldomiro. et al. Como usar as histórias em quadrinhos na sala de aula. 3. ed. São Paulo: Contexto, 2007.

SAUVÉ, Lucie. Uma cartografia das correntes em educação ambiental. In: SATO, M.; CARVALHO, I.C. M. (Orgs). Educação ambiental. Porto Alegre: Artmed, 2005.

TACHIZAWA, T. e MENDES, G. Como fazer monografia na prática. 12 ed. Rio de Janeiro: Editora FGV, 2006. 